\title{
EL LUGAR DEL CULTO DE ISIS EN LAS CIUDADES DE LA PENÍNSULA IBÉRICA*
}

\author{
POR \\ ELENA MUÑIZ GRIJALVO ${ }^{1}$ \\ Universidad Pablo de Olavide
}

\begin{abstract}
RESUMEN
A partir de la dedicatoria de una sacerdotisa de culto imperial de la colonia de Itálica (Santiponce, Sevilla) a varias divinidades femeninas (Victoria Augusta, Isis, Ceres y Juno), en este trabajo se explora el significado de la presencia de Isis y de la gens isiaca en espacios urbanos privilegiados: Isis como sustento de la ideología imperial, partícipe por tanto de los circuitos de culto de la ciudad de Itálica.
\end{abstract}

PALABRAS CLAVE: Isis; gens isiaca; culto imperial; Imperio Romano; Itálica.

\section{THE PLACE OF ISIAC CULT IN THE CITIES OF THE IBERIAN PENINSULA}

\author{
ABSTRACT \\ Recibido/Received 21-02-2019 \\ Aceptado/Accepted $\quad 12-09-2019$
}

Basing on a dedicatory to several goddesses (Victoria Augusta, Isis, Ceres and luno) by a priestess of imperial cult from the Roman colony of Italica (Seville, Spain), this paper analyses the place of Isis and the gens isiaca in privileged urban spaces: Isis was one of the pillars of imperial ideology and took part therefore in the civic circuits of cult in Italica.

KEY WORDS: Isis; gens isiaca; imperial cult; Roman Empire; Italica.

Cómo CITAR ESTE ARTículo / CitATION: Muñiz Grijalvo, Elena. 2021. «El lugar del culto de Isis en las ciudades de la península ibérica». Hispania Sacra LXXIII, 147: 11-17. https://doi.org/10.3989/hs.2021.001

La implantación del culto a Isis y a la gens isiaca en la península ibérica es un fenómeno que se remonta a época republicana. Aunque no muy abundantes, existen ejemplos de la introducción del culto ya a fines del siglo II a.C. en lugares como Ampurias, donde el alejandrino Numas hizo construir un templo, ${ }^{2}$ o Cartagena, lugar elegido por un tal Titus

\footnotetext{
Este trabajo ha sido realizado en el seno del Proyecto de Inves tigación «Discursos del Imperio Romano: Las procesiones y la construcción de la comunidad imperial» (PGC2018-096500-B-C32), del Ministerio de Ciencia, Innovación y Universidades. Deseo agradecer a Carole Gomez y al profesor Juan Antonio Martínez su amable invitación para participar en el Congreso «La implantación de nuevos fenómenos religiosos en la península ibérica (siglos III-XI. Aceptaciones, rechazos y compromisos» en la Casa de Velázquez (Madrid, 5-6 marzo 2018), donde presenté una primera versión de este trabajo, y a los revisores del artículo las interesantes sugerencias para su mejora, que espero haber sabido utilizar con provecho.

1 emungri@upo.es /

ORCID ID:https://orcid.org/0000-0003-0914-6842

2 CIL II 6185; IRC III, 15; IRC V, p. 83; RICIS 603/0701; Alvar Ezque-
} rra 2012, 125-133
Hermes para su fundación. ${ }^{3}$ Desde época flavia, no obstante, y en especial en los siglos II y III d.C., la diosa Isis apareció con frecuencia en espacios cívicos privilegiados y a veces en compañía de otros dioses.

Este trabajo se articula en torno a una singularísima inscripción aparecida en la ciudad bética de Itálica, entre los restos de un edificio que ha sido relacionado de manera habitual con el culto imperial. La inscripción, que ha sido datada a principios del siglo III, ${ }^{4}$ dice así:

Vict(oriae) · Aug(ustae) $\cdot$ Vib(ia) Modesta $\cdot$ C(aii) . Vib(ii) Libonis · fillia) · ori[g(ine)] / Mauretania $\cdot$ iterato

$3 A E$ 1982, $636=H E p$ 18, 2009, 255; RICIS 603/0202; Alvar Ezquerra $2012,160-162$.

4 AE 1983, 521; CILA III, 358; León-Castro 1982, 117, no 2; Blanco 1983, 8-13; ERItalica 22ter; HEp 4 (1994), 724; HEp 11 (2001), 472; RICIS 602/0201; Alvar Ezquerra 2012: no 83. La inscripción, sobre mármol, de medidas bastante reducidas (en su estado actual 12,5 x 37,5 $\mathrm{x}$ 36) y muy desgastada especialmente en el lado derecho y en la parte inferior, se conserva en el Museo Arqueológico de Sevilla. 
- honore bis flaminica sacerdo[s col(oniae) A(eliae) A(ugustae) I(talicae] / statuam · argenteam ex arg(enti) - p(ondo) · CXXXII (librarum) ((unciarum duarum semunciae)) cum · inauribus · trib(acis) [mar?]/garitis n(umero) $X \cdot$ et $\cdot g e(m)$ mis $\cdot n$ (umero) $X X X X \cdot$ et berull(is) n(umero) VIII - et corona aur[ea] / cum · gemis - n(umero) XXV . et gem · areis (!) ((sextantis)) - accept(o) $\cdot \operatorname{loc}(0) \cdot a b \cdot$ splendid(issimo) o[r]/dine $\cdot$ in templ(o) $\cdot$ suo $\cdot \operatorname{corona}(\mathrm{m})$ aurea $(\mathrm{m}) \cdot$ flaminal(em) - capitul(a) a aure [a / tr?] ia Isidis · alter(um) - Cerer(is) · cum m\{a\}an(li)b(us) . $\arg ($ enteis $) \cdot$ item $\cdot$ lunoni(s) r[eginae]

A la Victoria Augusta, Vibia Modesta, hija de Caius Vibius Libo, oriunda de Mauretania, honrada dos veces con el sacerdocio flamínico de la Colonia Elia Augusta Itálica por segunda vez, ofreció una estatua de plata, con un peso de 132 libras y 2 onzas y media de plata, con pendientes dorados con tres filas de 10 perlas, 40 piedras preciosas y 8 aguamarinas, así como una corona de oro con 25 piedras preciosas y $i 7$ ? joyeros, en el lugar indicado por el distinguidísimo Senado, en su templo, la corona flaminal de oro, tres cabecitas de oro, una de Isis, otra de Ceres con collares de plata, lo mismo de Juno Regina. ${ }^{5}$

Por motivos evidentes, la inscripción es de gran interés. Pero quedémonos en esta ocasión con la información que proporciona para analizar el lugar que ocupaba el culto de Isis en una ciudad como Itálica: una sacerdotisa de culto imperial, Vibia Modesta, que ofrece a la Victoria Augusta una estatua de plata (probablemente de la propia Victoria), más una cabecita de oro de Ceres, otra de Juno y otra de Isis, en un espacio de culto no relacionado de manera directa con los cultos isíacos. ${ }^{6}$

Antes de centrarnos en el significado de la presencia de Isis en aquel lugar, conviene recordar que la interpretación del espacio donde apareció la inscripción plantea varios interrogantes. Se trata de un complejo edilicio localizado en el centro de la vía principal que unía el anfiteatro con el antiguo foro, y situado en la parte más elevada de la ciudad. ${ }^{7}$ En el centro de un impresionante patio con un pórtico hecatostylos (aprox. $108 \mathrm{~m} \times 70 \mathrm{~m}$ ), flanqueado por amplias exedras rectangulares y semicirculares, se alzaban un templo sobre podio (probablemente octástilo y períptero) y un ara. La fecha de construcción y el diseño del espacio ${ }^{8}$ permiten relacionar este complejo con el emperador Adriano, promotor de la ampliación de la ciudad de Itálica. La interpretación del espacio es algo más controvertida. Identificado como un Traianeum en el momento de su excavación, las ofrendas a diferentes personalidades divinas (el Genio de la Colonia, Apolo Augusto, Júpiter, la Victoria Augusta, Ceres, Juno e Isis) y los restos escultóricos hallados dentro del recinto parecen hacer pensar más bien en un espacio de culto plural; y tal vez no solo de culto, sino polivalente, a la manera de los foros imperiales de la ciudad de Roma y de otros espacios también promocionados por Adriano, como la Biblioteca

\footnotetext{
5 La traducción es de Alvar Ezquerra 2012, nㅇ 83 (con ligeras modificaciones).

6 La traducción más habitual de capitul(a) ha sido bustos o cabecitas; cf. por ejemplo Oria Segura 2012, que cree que podría tratarse de cabecitas en la corona de flamínica de Vibia.

7 León-Castro 1988.

8 Con paralelos idénticos, entre otros, en la Biblioteca de Adriano en Atenas, el templo conocido como Hadrianeum en Roma, o el templo de Zeus Olímpico en Atenas, cf. por ejemplo León-Castro 1988; Boatwright 1997, 2000; Monaco, Corcella y Nuzzo 2014.
}

de Atenas. ${ }^{9}$ En todo caso, por su posición central y por lo extraordinario de sus dimensiones y de sus materiales, el lugar estaba sin duda relacionado con el gobierno local y con la casa imperial, que ocuparía una posición central en aquel espacio. La inscripción que comentamos podría haber estado relacionada con el lugar donde se veneraba a la Victoria Augusta dentro de aquel recinto, ${ }^{10}$ que tal vez fuese lo que el autor del texto calificó como in templo suo. Aunque carecemos de pruebas que lo demuestren, es probable que en algún rincón destinado al culto a la Victoria (¿tal vez en alguna de las exedras?) se dispusiera la ofrenda de Vibia Modesta, y que allí acabase recalando también la pequeña cabecita de oro de Isis.

La presencia de Isis en compañía de dioses ajenos a la familia isíaca fue un fenómeno habitual en todo el Mediterráneo, que generalmente se explica haciendo referencia a la inserción de Isis en los panteones cívicos de cada lugar, sin entrar en demasiados detalles sobre el significado preciso de este fenómeno. Pero ¿qué realidad cultual se escondía tras la aceptación de Isis en esos panteones, cuyos límites además resultan extremadamente difusos? Una forma de enfocar la cuestión sería afirmar que Isis fue gradualmente aceptada dentro del espectro de los cultos «públicos», como parece que ocurrió desde época helenística en muchos lugares del Mediterráneo. Pero la propia definición de «culto público» no está exenta de dificultades y es, de hecho, uno de los asuntos candentes en la historiografía actual sobre religiones antiguas. ${ }^{11}$ Ya no parece sensato conformarse con las definiciones de Cicerón o de Festo, quienes afirmaban que eran "públicos» aquellos cultos que se celebraban a expensas del estado y en nombre de la ciudadanía. ${ }^{12}$ Aunque los límites de lo «público» fueron con seguridad mucho más fluidos de lo que estas definiciones sugieren, es más que probable que en efecto el culto de Isis fuera de alguna manera "público», porque se asentó en lugares sancionados por los órganos ciudadanos ${ }^{13}$ y a menudo de manifiesto uso público (edificios para espectáculos o inmediaciones del foro) ${ }^{14}$ porque recibió dinero público ${ }^{15}$ y porque en ocasiones incluso se puso a su disposición fuerza de trabajo pública para edificar sus santuarios. ${ }^{16}$

No obstante, más allá de que el culto de la gens isiaca recibiera sanción o financiación pública, creo que el caso

9 Luzón y Castillo 2007, Cortés Copete 2010. Alarcón Hernández 2016, 295 resume el asunto con claridad: se trataría de un espacio dedicado al culto imperial «entendiendo esta denominación en el más amplio de sus sentidos».

10 La inscripción fue hallada en «una caseta adosada a la fachada que daba al cardo máximo [...] A este lugar se llevaron enteros y ya rotos los tres bloques de mármol» (uno de ellos la inscripción que nos ocupa). «Los tres son basas de esculturas» (Blanco 1983, 1).

11 Cito solo algunas de las muchas obras que recogen la polémica sobre la definición de "público» y "privado» en el ámbito de las religiones antiguas: Polignac y Schmitt Pantel 1998; Dasen y Pierart 2005; Bowes 2008; Ando y Rüpke 2015.

12 Fest. s.v. Publica sacra; Cic. de Harusp. Resp. 7.

13 Hay multitud de ejemplos de santuarios situados en lugares «públicos» con permiso del orden decurional y de las autoridades pertinentes: algunos ejemplos en RICIS 502/302, 502/701, 502/702, 507/101, 514/401,609/101, 610/105.

14 Para los santuarios de Isis en complejos teatrales, cf. Fontana 2010, 73-74 (contra) y Gasparini 2013 y 2018.

15 Ver por ejemplo $A E$ 1992, 1412 = RICIS 613/703: construido con los fondos de Apolo por decisión pública.

16 CIL VIII $2629=$ RICIS 704/301; CIL VIII $2631=$ RICIS 704/303. 
de Itálica invita a imaginar algo más. Este trabajo pretende mostrar que el culto de Isis llegó a formar parte de un contexto cultual común, un entramado ritual cívico en el que participaban dioses de procedencias diversas. Habitualmente la dura realidad obliga a conformarse con un acercamiento fragmentado y tergiversador a la vida religiosa de las ciudades antiguas. Los distintos cultos suelen estudiarse de manera aislada: por un lado, los cultos cívicos tradicionales (sin precisar demasiado cuáles serían); por otro, el culto imperial; y, siempre como una categoría aparte, las religiones orientales y otros cultos recién llegados, como el cristianismo. Desde luego, existen motivos que explican esta tendencia a fragmentar la realidad: los testimonios arqueológicos resultan a menudo extraordinariamente difíciles de interpretar, y carecen por lo general de contextos bien definidos; los estudiosos se especializan en sus propias parcelas de saber, levantando barreras invisibles entre mundos rituales que seguramente no fueron compartimentos estancos. Por estos motivos resulta a menudo imposible concebir la vida religiosa de la ciudad en su conjunto, e imaginar la existencia de circuitos de culto comunes o el paisaje religioso que percibían los habitantes de las ciudades. Partiendo de la extraordinaria inscripción de Vibia Modesta, el objetivo de este estudio es desentrañar el significado de la probable presencia de la diosa Isis en un edificio probablemente relacionado con el culto imperial y con otros cultos de la ciudad de Itálica, y qué puede deducirse en general de la ubicación de los santuarios isíacos en las ciudades de la península ibérica.

Para empezar, es necesario recordar que disponemos de muy pocos datos que ayuden en este empeño. Aunque los materiales relacionados con el culto a Isis en la península ibérica son numerosos, ${ }^{17}$ en la mayor parte de los casos carecen de un contexto cultual que permita comprender su uso en el ritual isíaco, y menos aún sus posibles vínculos con otros cultos. Si comenzamos por preguntarnos sobre la ubicación de los santuarios, existen muy pocos casos en los que ésta se conozca de manera precisa. Distintos estudios han descubierto la probable existencia de santuarios isíacos en ciudades como Tarragona, ${ }^{18}$ Sagunto, ${ }^{19}$ Cabra, ${ }^{20}$ Alameda ${ }^{21}$ o Mérida, ${ }^{22}$ por ceñirnos solo a los casos más célebres; pero apenas se sabe nada más sobre ellos. Desde luego, es más que probable que hubiese santuarios en muchos otros lugares, por ejemplo en Alcalá del Río, donde una espléndida cabeza colosal de la diosa Isis probablemente formara parte de la estatua de culto de un santuario hoy desconocido. ${ }^{23}$ Pero, a día de hoy, tan solo podemos estar seguros de la ubicación de un número muy reducido de santuarios: el ya mencionado de Ampurias, el o los iseos de Cartagena, el iseo de Baelo Claudia (Bolonia), el de Panóias y el de Itálica.

17 Cf. el catálogo publicado por Alvar (2012), disponible también ahora y actualizado en la web La gens isiaca en Hispania: http://www. uc3m.es/gens-isiaca. Cf. también Alvar y Muñiz 2002 y 2004.

18 Alföldy 1993, 22; Alvar 2012, 105.

19 Alvar Ezquerra 2012, 106; Alvar y Gasparini 2020.

20 Alvar Ezquerra 2012, 88; Alvar y Gasparini 2020.

21 CIL II2 5, 912; RICIS 602/0301; Alvar 2012: no 119. Cf. Beltrán Fortes y Atencia 1996.

22 Alvar Ezquerra 2012, 47; Alvar y Gasparini 2020.

23 García y Bellido 1949, n. 136, Pl. 103; García y Bellido 1967, 115; Mora 2007, 317-319; Beltrán 2008, 258, fig. 6; Beltrán y Mercado 2010, 1140.
Dejando aparte el caso de Ampurias, cuyo horizonte social y cultual lo convierten en un caso especial, los demás santuarios con ubicación conocida comparten una característica común: todos ellos estaban situados en espacios urbanos privilegiados. En todos los casos (a excepción del singular santuario de Panóias) se trataba de lugares perfectamente visibles, muy transitados, insertos en el tejido institucional de cada ciudad. El ejemplo más claro es sin duda el de Baelo, donde el iseo compartía su exclusiva ubicación con los tres templos en honor de Júpiter, Juno y Minerva, coronando el foro de la ciudad. ${ }^{24} \mathrm{El}$ iseo, de época flavia, tenía además unas dimensiones considerables (aprox. $530 \mathrm{~m}^{2}$ ) y debía resultar muy llamativo para los viandantes y, sobre todo, para quienes visitaban la ciudad por vez primera. Aunque estaba rodeado por un muro rectangular, que impedía la visión del interior, la extraordinaria situación del santuario hace pensar que las actividades cultuales no se limitaban a las propias de una comunidad de isíacos: el alcance de las fiestas y de las procesiones probablemente involucraba en mayor o menor medida a toda la población.

Algo parecido puede pensarse en el caso del probable santuario de época flavia en Cartagena. Hasta el momento han aparecido en la ciudad dos posibles lugares isíacos: el primero, de época republicana, se encontraba en la parte superior del Cerro del Molinete (en la conocida como Arx Hasdrubalis) y parece que estaba relacionado con otro espacio sagrado en honor de divinidades de origen sirio. ${ }^{25} \mathrm{El}$ segundo, que aún no ha sido identificado con certeza, está al pie de la colina, muy cerca del foro. ${ }^{26}$ Parece que puede datarse en el siglo I d.C. y podría tener relación con un edificio para banquetes, unas termas y una palestra que han aparecido en las inmediaciones, como en el caso del serapeum de Ostia. ${ }^{27}$ De ser así, la presencia de la gens isiaca en la ciudad habría ido ganando en importancia y conquistando un espacio cada vez más central.

Una posición de primer orden tuvo también sin duda el tercer caso que deseo presentar, en el que se basa además buena parte de mis argumentos: se trata del llamado iseo de Itálica, un santuario de amplias proporciones que se ubicó en el pórtico trasero del teatro de la ciudad. Lo que en el momento de su hallazgo en 1989 parecía ser solo un pequeño templete encastrado en el lado norte del pórtico trasero del teatro, ${ }^{28}$ en las excavaciones de 2008-2009 se reveló como un santuario isíaco en toda regla, de dimensiones mucho mayores de lo esperado. ${ }^{29}$ El templo próstilo y tetrástilo fue construido en efecto aprovechando el lado norte del pórtico, pero lo rebasaba con creces, extendiéndose en su mayor parte fuera del pórtico $(17,5 \mathrm{~m} . \times$ 9,5 m.). Pero además, el enorme patio porticado albergaba un estanque rectangular alineado con la entrada principal del templo, un altar cuadrangular también en línea con el templo, un focus o depósito de cenizas y, lo más llamativo de todo, una cripta subterránea en forma de L. ${ }^{30}$ Todos aquellos elementos,

\footnotetext{
24 Dardaine et al. 2008. Bendala Galán 2010 propone una adscripción alternativa de estos tres templos.

25 Alvar 2012, 112; Alvar y Gasparini 2020.

$26 \quad$ Noguera et al. 2016, 386-387; Alvar y Gasparini 2020.

27 Mar 2001; Alvar Ezquerra, Rubio Rivera y López Barja de Quiroga 2002.

28 Corzo 1991; Rodríguez 2004.

29 Jiménez, Rodríguez e Izquierdo 2013; Jiménez 2020.

30 Muñiz 2020.
} 
para los que se ha propuesto recientemente una fecha de entre finales del siglo I d.C. y mitad del siglo II d.C., ${ }^{31}$ más otros muchos que sin duda han desaparecido (decoración arquitectónica, escultórica y vegetal), conferían un marcado carácter isíaco a aquel espacio singular.

A juzgar por la gran variedad de formas, dimensiones, decoraciones y elementos cultuales de los santuarios isíacos que han sido hallados en el Mediterráneo, la tipología de estos santuarios no era única, sino muy variopinta;; muchos de sus elementos serían fácilmente reconocibles para los habitantes de las ciudades, y el pórtico del teatro de Itálica sin duda adquirió un inconfundible ambiente nilótico. Ahora bien, aquel espacio probablemente continuó teniendo un carácter abierto. Aunque en ocasiones se ha propuesto que la inauguración del santuario supuso la privatización y el cierre del pórtico, ${ }^{33}$ el carácter de aquel espacio hace poco probable que así fuera. Desde la construcción del pórtico en el siglo I d.C., el lugar se había convertido en uno de los enclaves preferidos para la celebración del poder de las elites, como recuerda la inscripción de Lucio Pontio, a quien su hija dedicó una estatua ecuestre situada en el lado oeste. ${ }^{34}$ Antes de la construcción del iseo, el pórtico tenía una entrada monumental por su lado norte, y es probable que tuviera otras en los lados sur y este. Precisamente la vía que lo recorría por el lado este fue ampliada en el siglo II d.C. ${ }^{35}$ De hecho, parece que toda la zona ganó en importancia durante la primera mitad del siglo II: en la parte superior de la cavea se ha excavado recientemente parte de una enorme estructura de finalidad incierta, probablemente de época adrianea, que debía tener una importancia señalada en la vida de la ciudad, por su localización, por sus dimensiones y porque las mejores piezas de la estatuaria italicense han sido halladas precisamente en aquella zona. ${ }^{36}$ Además, el teatro estaba muy cerca de la zona portuaria de la ciudad, ${ }^{37}$ que debió de estar extremadamente animada durante la impresionante ampliación de Itálica que tuvo lugar por iniciativa de Adriano: enormes barcazas cargadas de mármol de las canteras egipcias, de las minas de Asia y de las islas del Egeo surcaban en aquellos años las aguas del brazo del Guadalquivir que bordeaba Itálica, proporcionando a toda aquella zona una animación sin precedentes.

Por todos estos motivos, parece probable que la porticus post scaenam del teatro de Itálica no quedase cerrada al tránsito tras la construcción del iseo, o al menos no completamente. Desde luego, el templo sí que podía cerrarse, como revelan además las huellas de una cancela en el umbral de entrada; ${ }^{38}$ y es probable que la cripta subterránea también tuviera algún tipo de cierre que preservara tanto el continente como el contenido de ojos profanos, como se ha comprobado en criptas similares en otros lugares del

\footnotetext{
31 Jiménez, Rodríguez e Izquierdo 2013; Jiménez 2020.

32 Sobre la morfología de los santuarios de Isis en el Mediterráneo, consultar sobre todo el trabajo monográfico de Kleibl 2009; cf. también Nielsen 2014.

33 Corzo 1991; Rodríguez 2004, 263-264; Dardaine et al. 2008, 181.

34 ERItalica $61=A E 1985,550=$ CILA II, 399.

35 Rodríguez 2004, 345.

36 Jiménez, Rodríguez e Izquierdo 2013, 274-280.

37 Beltrán 2013; Jiménez y Borja 2015; González-Muñoz 2018.

38 Corzo 1991, 128.
}

Imperio. ${ }^{39}$ Pero el pórtico en su conjunto pudo continuar sirviendo para otros fines. Entre ellos, creo que merece la pena destacar un aspecto al que no se ha prestado especial atención en el caso de Itálica: el uso ceremonial de este tipo de pórticos y del teatro en general pudo hacer que el culto de Isis quedase integrado en una dinámica ritual de más amplio espectro.

Desde que se pusieron de moda con la construcción del pórtico del teatro de Pompeyo en Roma, los pórticos traseros se destinaron al esparcimiento de los ciudadanos, pero también a usos rituales habitualmente vinculados al culto imperial. ${ }^{40}$ De hecho, los edificios teatrales en sí mismos formaban parte esencial de la vida religiosa de la ciudad, porque podían albergar ceremonias y representaciones sagradas de todo tipo. ${ }^{41} \mathrm{~A}$ menudo se convirtieron, por ejemplo, en el lugar de llegada de las procesiones de culto imperial y en escenario de ritos en honor de la familia del emperador, cuyas estatuas y altares adornaban la escena. Existen ejemplos muy bien conocidos de procesiones que comenzaban su recorrido en el templo de culto imperial y que discurrían por las principales vías ciudadanas, realizando paradas en los lugares más señalados de la geografía sagrada de la ciudad: el anfiteatro, el circo y los templos ciudadanos, que probablemente eran engalanados a su vez con altares y con decoración ad hoc. ${ }^{42}$ Este tipo de procesiones, que habitualmente se relacionaba con la casa imperial, incluía también a héroes fundadores y a otras divinidades señaladas en la vida religiosa de la ciudad.

El entorno del teatro, por tanto, constituía un espacio ceremonial de primer orden. Parece probable, en consecuencia, que la elección de este enclave para el culto de Isis en Itálica guardase alguna relación con el marco en que se inscribía. Aunque no es demasiado frecuente, se conocen otros casos de proximidad entre santuarios isíacos y teatros. La península ibérica, de hecho, ha proporcionado otros dos ejemplos interesantes. En Regina (Baños de la Reina, Badajoz) ha aparecido una estatua acéfala de Isis en las proximidades del teatro. ${ }^{43}$ Aunque no se han encontrado evidencias del iseo de la ciudad, es probable que la estatua fuese una imagen de culto y que la ubicación del santuario de Isis, probablemente de época flavia o antonina, guardase alguna relación con el teatro. El segundo ejemplo es igualmente elocuente: se trata de otra estatua de Isis, probablemente también de culto, hallada en el solar del antiguo teatro de Clunia (Coruña del Conde, Burgos), y que además podría haber estado relacionada de alguna manera con el interés del emperador Adriano por estos cultos. ${ }^{44}$ Cerca de la estatua se ha encontrado una dedicatoria por la salud de Adriano, ${ }^{45}$ y sabemos que el propio emperador pasó por la ciudad en uno de sus viajes. ${ }^{46}$

39 Para las criptas y los llamados «nilómetros» en los iseos, cf. Wild 1981; Kleibl 2007.

40 Ramallo 2000, 110-112.

41 Gros 1990, 2006; Rosso 2009.

42 Algunos ejemplos muy célebres son las procesiones en Éfeso (Rogers 1991a), Enoanda (Rogers 1991b), o Gythion (Gorrini y Calandra 2008).

43 Alvar Ezquerra 2012, no 66.

44 Alvar Ezquerra 2012, FC 012; pero cf. ahora Alvar y Gasparini 2020, que admiten el hallazgo entre las posibles ruinas de un templo.

45 Gutiérrez Behemerid 2011.

46 Birley 2003, 196. 
La presencia de Isis en el teatro de Itálica y en otros teatros, por tanto, pudo significar que los santuarios isíacos estuvieran incluidos en circuitos rituales más amplios, relacionados con el culto imperial o con otros ritos ciudadanos. Los lugares sagrados de Isis eran enclaves religiosos de primer orden y, como tales, podían constituir estaciones señaladas para las grandes procesiones cívicas, o decorados pintorescos para todo tipo de ritos. En el caso de Itálica, además, contamos con un testimonio excepcional: la propia diosa Isis estuvo presente al menos en otro lugar de la ciudad, en el complejo cultual situado en el centro de la ampliación adrianea, como puede leerse en la inscripción que da origen a estas páginas. Hay otro detalle interesante: en dicho templo, Isis estaba presente en forma de busto de oro de pequeñas dimensiones, igual que Ceres y Juno, por lo que no sería descabellado pensar que aquellas pequeñas cabecitas formaran parte de procesiones de corte cívico, que conectaban los principales lugares religiosos de la ciudad. ${ }^{47}$ Aunque en el caso de Itálica no se han encontrado hasta la fecha muchos otros espacios religiosos, es de suponer que al menos estos dos enclaves excepcionales (el gran santuario y el teatro) estuvieron conectados por este tipo de procesiones. La pequeña cabeza de Isis invita incluso a imaginar que una de las paradas se produjera justo antes de que la procesión llegase a su destino, en el propio iseo del teatro.

Más allá de los ritos particulares que formaban parte del culto isíaco (iniciaciones, procesiones, sacrificios etc.), que con seguridad tuvieron lugar en santuarios como el de Itálica, el análisis de la ubicación del culto de Isis en las ciudades aporta una nueva perspectiva para su estudio. Algo parecido ocurre con la posibilidad de que Isis estuviese presente en espacios sagrados ajenos, o de que mantuviese algún tipo de relación con dioses que no pertenecían a la familia isíaca. Aunque no es muy habitual, hay algunos testimonios de la presencia de Isis en santuarios de otros dioses. Los casos más significativos quedan fuera de la península ibérica, pero también aquí hallamos a Isis en un complejo termal en la localidad de Aquae Calidae, ${ }^{48}$ por ejemplo, o en el amplio espacio cultual central de la ciudad de Itálica. La diosa del Nilo probablemente participase en ritos que incluían a divinidades de distinto origen.

De nuevo la ciudad de Itálica proporciona un ejemplo interesante a este respecto. En el umbral del templo de Isis han aparecido varias ofrendas a la diosa en forma de plantae pedum. ${ }^{49}$ Como suele ocurrir en este tipo de exvotos, los textos son muy convencionales y aportan poca información sobre los fieles o sobre el culto de la diosa en general. No obstante, una de las inscripciones contiene un detalle interesante: [Isi]di vi(ctrici) Privata imperio lunonis $d$ (ono) $d$ (edit) («A Isis victoriosa, por orden de Juno, Privata ofreció (esto como) regalo»). Es decir, la ofrenda a Isis se había hecho por mandato de la diosa Juno.

47 Cf. Fishwick 1991, 541-563; Madigan 2012, 1-38.

48 Alvar Ezquerra 2012, no 139.

49 Canto 1984, 190; HEp 5, 1995, 714 = Corzo 1991, 128, $133=$ RICIS 602/0202 = Alvar 2012, no 70: Isidi Dominae /Marcia Voluptas ex voto / et iussu libens animo sol(vit); HEp 5, 1995, $715=$ RICIS 602/0203 = Alvar 2012, no 71: Isidi / Regin(ae) / Soter / votum / s(olvit) I(ibens) a(nimo); HEp 5, 1995, 716 = RICIS 602/0204 = Alvar 2012: no 72: Domnulae Bubasti / Iunia Cerasa / v(otum) s(olvit) I(ibens) a(nimo); HEp 5, 1995, $717=$ RICIS 602/0205 = Alvar 2012, no 31: [Isi]di Vi(ctrici) / Privata imperio lunonis / d(onum) $d$ (edit).
Qué realidad cultual podía esconderse tras este tipo de inscripciones, constituye en sí mismo un tema apasionante. ${ }^{50}$ Para empezar, habría que plantearse cómo se produjo la orden de Juno: habitualmente se cree que este tipo de ofrendas con fórmulas como viso/iussu etc. implicaba algún tipo de comunicación con la diosa (en este caso Juno), directamente o a través de personal especializado, y estaba relacionado con prácticas como la incubación. Pero no debemos descartar otro tipo de explicaciones para estas fórmulas, que aluden a la difusión de un cierto tono servil en la comunicación de los dioses, que hizo que se popularizasen este tipo de fórmulas "por mandato de» el dios en cuestión. ${ }^{51}$ Sea como fuera, en este caso Juno tenía algo que ver con aquella ofrenda a Isis. Las ofrendas a los dioses por mandato de otros dioses eran habituales, aunque en la mayor parte de los casos también se desconoce por qué se hacían: ${ }^{52}$ los dioses podían tener una relación mitológica, podían compartir un mismo espacio sagrado, o sencillamente podía tratarse de preferencias personales del devoto en cuestión.

Probablemente nunca sabremos qué llevó a Privata a ofrecer aquella placa por mandato de Juno, una diosa que rara vez aparece vinculada a Isis. ${ }^{53}$ Pero sería imperdonable no reparar en la coincidencia de que, precisamente en Itálica, Isis y Juno se hicieron compañía al menos en otra ocasión, gracias a la ofrenda de Vibia Modesta. El regalo de aquella dama mauritana, sacerdotisa de las emperatrices, a la Victoria Augusta suponía la relación de una serie de diosas con el culto imperial. La selección de aquellas diosas probablemente tuvo que ver con las virtudes que encarnaban Isis, Juno y Ceres, entre otras, la fertilidad y la maternidad. ${ }^{54}$ En el templo de culto imperial, pero también en el iseo, se estaba poniendo de manifiesto la relación de Isis y Juno con las virtudes que formaban parte de la ideología del culto imperial. De esta y de otras muchas maneras, la potencia teológica de los dioses del Nilo desbordó los límites propios de su culto y se transformó en uno de los pilares de las religiones ciudadanas en el Mediterráneo de época romana.

En conclusión, la excepcional ofrenda de Vibia Modesta descubre todo un mundo de posibilidades para reflexionar sobre el lugar que ocupó el culto a Isis en la península ibérica y, con seguridad, en otros lugares del Imperio. Isis colaborando con otros dioses en el refuerzo de la ideología imperial, o participando de distintas maneras en procesiones y en redes rituales cívicas, son solo algunas propuestas para reconsiderar la dinámica de la vida religiosa en el Mediterráneo antiguo.

\section{ABREVIATURAS}

$\begin{array}{ll}A E & \text { L'Année Epigraphique. Paris } \\ \text { CIL } & \text { Corpus Inscriptionum Latinarum } \\ \text { CILA } & \text { Corpus de Inscripciones Latinas de Andalucía }\end{array}$

50 Cf. Zugravu 1996-1997; Kajava 2009; Belfaida 2012; Tantimonaco 2016; Renberg 2017; Alvar Nuño 2019; Muñiz 2020; Gasparini, en prensa.

51 Veyne 1986, 267-70.

52 Kajava 2009; Renberg 2018.

53 Hasta la fecha solo han aparecido relacionadas en $A E 1938,63$ $=$ RICIS 501/0128 (Roma, II d.C.); CIL IX $5179=$ RICIS 509/0101 (Asculum, I d.C.) y RICIS Suppl. I, 504/0406 (Pozzuoli, II d.C.).

54 Beaujeu 1955, 419-423; Mikocki 1995; Christodoulou 2015. 
ERItalica Epigrafía Romana de Itálica

HEp Hispania Epigraphica

IRC Inscriptions Romaines de Catalogne

RICIS Recueil des inscriptions concernant les cultes isiaques

\section{BiBLIOgRAFÍA}

Alarcón Hernández, Carmen. 2016. La religión del poder en Hispania: las manifestaciones de culto imperial en la provincia de la Bética durante el principado. Tesis Doctoral. Universidad de Sevilla.

Alföldy, Géza. 1993. «Tarraco y la Hispania romana: cultos y sociedad». En Religio Deorum. Actas del Coloquio Internacional de Epigrafía "Culto y sociedad en Occidente». Sabadell: Ausa.

Alvar Ezquerra, Jaime. 2012. Los cultos egipcios en Hispania. Besançon: Presses Universitaires de Franche-Comté.

Alvar Ezquerra, Jaime y Valentino Gasparini. 2020. «The 'gens isiaca' in Hispania. Contextualising the iseum at Italica». Bibliotheca Isiaca, IV. Burdeos: Ausonius.

Alvar Ezquerra, Jaime y Elena Muñiz Grijalvo. 2002. «Testimonios del culto a Isis en Hispania». En Ex oriente lux: las religiones orientales antiguas en la Península Ibérica, ed. Eduardo Ferrer, 245-258. SeviIla: Servicio de Publicaciones de la Universidad de Sevilla.

Alvar Ezquerra, Jaime y Elena Muñiz Grijalvo. 2004. «Les cultes égyptiens dans les provinces romaines d'Hispanie». En Isis en Occident, ed. Laurent Bricault, 69-94. Leiden: Brill.

Alvar Ezquerra, Jaime, Rebeca Rubio Rivera y Pedro López Barja de Quiroga. 2002. «El serapeo de Ostia». ARYS 5: 99-122.

Alvar Nuño, Antón. 2019. «Making sense of individual crisis: Votive offerings and narratives in the Roman world». Studi e materiali di storia delle religioni 85: 270-284.

Ando, Clifford y Rüpke, Jörg. 2015. Public and private in Ancient Mediterranean law and religion. Berlín - Munich - Boston: De Gruyter.

Beaujeu, Jean. 1955. La religion romaine à l'apogée de l'empire. Vol. 1: La politique religieuse des Antonins (96-192). París: Les Belles Lettres.

Belfaida, Abdelaziz. 2012. "Les formules ex visu et ex iussu dans l'épigraphie religieuse de l'Afrique romaine». En L'Africa romana: trasformazione dei paesaggi del potere nell'Africa settentrionale fino alla fine del mondo antico: atti del XIX convegno di studio, Sassari, 16-19 dicembre 2010, ed. Mari Bastiana Cocco, Alberto Gavini y Antonio Ibba vol. 2, 2161-2171. Roma: Carocci.

Beltrán Fortes, José. 2008. «Cultos orientales en la Baetica romana. Del coleccionismo a la Arqueología». En Culti orientali tra scavo e collezionismo, ed. Beatrice Palma Venetucci, 249-272. Roma: Artemide.

Beltrán Fortes, José. 2013. «Mármoles en la Bética durante el reinado de Adriano: el protagonismo de Italica». En Roma, Tibur, Baética: investigaciones adrianeas, ed. Pilar León y Rafael Hidalgo, 225250. Sevilla: Universidad de Sevilla.

Beltrán Fortes, José y Rafael Atencia. 1996. «Nuevos aspectos del culto isiaco en la Baetica». Spal 5: 171-196.

Beltrán Fortes, José y Laura Mercado Hervás. 2010. «Pelagia en Hispalis (Sevilla)». En Dialéctica histórica y compromiso social. Homenaje a Domingo Plácido, ed. César Fornis, Julián Gallego, Pedro López Barja y Miriam Valdés, 1129-1141. Zaragoza: Marcial Pons.

Bendala Galán, Manuel. 2010. «Baelo Claudia y su personalidad ciudadana y urbana: diálogo desde el estudio y la amistad». Pallas 82: 465-481. https://doi.org/10.4000/pallas.13208

Birley, Anthony. 2003. Adriano. Barcelona: Atalaya.

Blanco, Antonio. 1983. «Nuevas inscripciones latinas de Itálica». Boletín de la Real Academia de la Historia 180: 1-20.

Boatwright, Mary. 1997. "The Traianeum in Italica (Spain) and the Library of Hadrian in Athens». En The interpretation of architectural sculpture in Greece and Rome, ed. Diana Buitron-Oliver, 193-217. Washington: National Gallery of Art.

Boatwright, Mary. 2000. Hadrian and the cities of the Roman empire. Princeton: Princeton University Press.
Bowes, Kim. 2008. Private worship, public values and religious change in late Antiquity. Cambridge: Cambridge University Press.

Canto de Gregorio, Alicia. 1984. "Les plaques votives avec plantae pedum d'Italica: un éssai d'interprétation». Zeitschrift für Papyrologie und Epigraphik 54: 183-194.

Christodoulou, Perikles. 2015. "Sarapis, Isis, and the emperors». En Romanising oriental gods? Religious transformations in the Balkan provinces in the Roman period. New finds and novel perspectives, 167-211. Skopje: Makedonska akademija na naukite i umetnostite.

Cortés Copete, Juan Manuel. 2010. «¿Un Traianeum en Itálica?». En Dialéctica histórica y compromiso social. Homenaje a Domingo Plácido, 583-596. Zaragoza: Pórtico.

Corzo, Jorge Ramón. 1991. «Isis en el teatro de Itálica». Boletín de BeIlas Artes 19: 125-148.

Dardaine, Sylvie, Myriam Fincker, Janine Lancha y Pièrre Sillières, eds. 2008. Belo VIII. Le sanctuaire d'Isis. Collection de la Casa de Velázquez, CVII. Madrid: Casa de Velázquez.

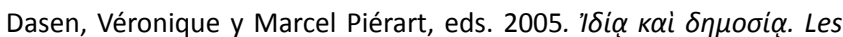
cadres "privés» et "publics» de la religion grecque antique. Actes du IXe colloque du Centre International d'Études de la Religion Grecque Antique (CIERGA), tenu à Fribourg du 8 au 10 septembre 2003. Liège: Centre International d’Étude de la Religion Grecque Antique.

Fishwick, Duncan. 1991. The imperial cult in the Latin West: studies in the ruler cult of the western provinces of the Roman Empire, vol. II.1. Leiden - New York: Brill.

Fontana, Federica. 2010. I culti isiaci nell'Italia settentrionale. 1: Verona, Aquileia, Trieste. Trieste: Edizioni Università di Trieste.

García y Bellido, Antonio. 1949. Esculturas romanas de España y Portugal. Madrid: CSIC.

García y Bellido, Antonio. 1967. Les religions orientales dans l'Espagne romaine. Leiden: Brill.

Gasparini, Valentino. 2013. "Staging religion. Cultic performances in (and around) the Temple of Isis in Pompeii». En Memory and religious experience in the Greco-Roman world, ed. Nicola Cusumano, Valentino Gasparini, Attilio Mastrocinque y Jörg Rüpke, 185-211. Stuttgart: Franz Steiner.

Gasparini, Valentino. 2018. «Les acteurs sur scène. Théâtre et théâtralisation dans les cultes isiaques». En The Greco-Roman cults of Isis. Agents, images and practices. Proceedings of the VIth International Conference of Isis Studies (Erfurt, May 6-8 2013 - Liège, September 23-24 2013), ed. Valentino Gasparini y Richard Veymiers. Vol. 2, 714-746 Leiden-Boston: Brill.

Gasparini, Valentino. En prensa. «Isis' footprints. The petrosomatoglyphs as spacial indicators of human-divine encounters». En Sensorium. Sensory Perceptions in Roman Polytheism, ed. Antón Alvar Nuño, Jaime Alvar Ezquerra y Greg Woolf. Leiden \& Boston: Brill.

González-Muñoz, Manuel Alejandro. 2018. «Italica et Baetis». Revista Bajo Guadalquivir y Mundos Atlánticos 1: 141-164.

Gorrini, María Elena y Elena Calandra. "Cult practice of a pompé in the imperial age: SEG XI, 923». Sparta 4 (2): 3-22.

Gros, Pierre. 1990. «Théâtre et culte impérial en Gaule Narbonnaise et dans la Péninsule Ibérique». En Stadtbild und Ideologie. Die monumentalisierung hispanicher Städte zwischen Republik und Kaiserzeit, ed. Walter Trillmich y Paul Zanker, 381-390. Munich: Bayerische Akademie der Wissenschaften.

Gros, Pierre. 2006. «Les theatres des provinces occidentales. Le problème des modeles architecturaux et ideologiques». En Jornadas sobre teatros romanos en Hispania, ed. Carlos Márquez y Ángel Ventura, 15-27. Córdoba: Universidad de Córdoba.

Gutiérrez Behemerid, María Ángeles. 2011. «La interpretación de los modelos urbanos en la ciudad de Clunia». En Roma y las provincias: modelo y difusión, ed. Trinidad Nogales e Isabel Rodá, 817828. Roma: L'Erma di Bretschneider.

Jiménez, Álvaro. 2020. "The Iseum of Italica. A sanctuary in the theater's porticus». Bibliotheca Isiaca IV, 45-51. Burdeos: Ausonius.

Jiménez, Álvaro, Olivia Rodríguez y Rocío Izquierdo. 2013. «Novedades arqueológicas adrianeas en el teatro de Itálica y su entorno». En Roma, Tibur, Baetica. Investigaciones adrianeas, ed. Rafael Hidalgo y Pilar León-Castro, 271-292. Sevilla: Universidad de Sevilla. 
Jiménez, Álvaro y Francisco Borja. 2015. «El teatro de Itálica y su entorno. Evolución del paisaje urbano entre el s. II a.C. y el cambio de era». En Actes 2on Congrés Internacional d'Arqueologia i món antic. August $i$ les províncies occidentals. 2000 aniversari de la mort d'August. Vol. II, 87-93. Tarragona: Fundació Privada Mútua Catalana.

Kajava, Mika. 2009. "Osservazioni sulle dediche sacre nei contest oracolari». En Dediche sacre nel mondo greco-romano. Diffusione, funzioni, tipologie. Religious dedications in the Greco-Roman World, Distribution, Typology, Use, ed. John Bodel y Mika Kajava, 209-226. Roma: Institutum Romanum Finlandiae.

Kleibl, Kathrin. 2007. «Water-crypts in sanctuaries of Graeco-Egyptian deities of the Graeco-Roman period in the Mediterranean region». En Proceedings of the Fourth Central European Conference of Young Egyptologists, 31 August-2 September Budapest, 207-223. Studia Aegyptiaca, 18. Budapest: NKTH.

Kleibl, Kathrin. 2009. Iseion. Raumgestaltung und Kultpraxis in den Heiligtümern gräco-ägyptischer Götter des antiken Mittelmeerraumes. Worms: Wernersche Verlagsgesellschaft.

León-Castro Alonso, Pilar. 1982. "La zona monumental de la Nova Urbs». En Itálica (Santiponce, Sevilla). EAE, 12. Madrid: Ministerio de Cultura.

León-Castro Alonso, Pilar. 1988. Traianeum de Itálica. Sevilla: Monte de Piedad y Caja de Ahorros de Sevilla.

Luzón, José María y Elena Castillo Ramírez. 2007. «Evidencias arqueológicas de los signos de poder en Itálica». En Culto imperial: política y poder, coord. Trinidad Nogales y Julián González, 192-213. Roma: L'Erma di Bretschneider.

Madigan, Brian. 2012. The ceremonial sculptures of the Roman gods. Leiden: Brill.

Mar, Ricardo. 2001. El santuario de Serapis en Ostia. Tarragona: Universitat Rovira i Virgili.

Mikocki, Tomasz. 1995. Sub specie deae: les impératrices et princesses romaines assimilées à des déesses: étude iconologique. Roma: G. Bretschneider.

Monaco, Maria Chiara, Aldo Corcella y Elsa Nuzzo. 2014. «Significato e funzioni della cosiddetta Biblioteca di Adriano ad Atene». En Adriano e la Grecia, ed. Elena Calandra y Benedetta Adembri, 4960. Milán: Electa Mondadori.

Mora, Gregorio. 2007. «Testimonios de religión pagana en Ilipa Magna». En Ilipa Magna. De la Prehistoria a la época romana, ed. Eduardo Ferrer, Álvaro Fernández, José Luis Escacena y Araceli Rodríguez, 311-320. Alcalá del Río: Ayuntamiento de Alcalá del Río.

Muñiz Grijalvo, Elena. 2020. "The cult of Isis in Italica». Bibliotheca Isiaca IV. Burdeos: Ausonius.

Nielsen, Inge. 2014. Housing the chosen: the architectural context of mystery groups and religious associations in the ancient world. Turnhout: Brepols.
Noguera, José Miguel, María José Madrid, Victoria García y Víctor Velasco. 2016. "Edificio del atrio, Carthago Nova (Cartagena, Murcia)». En Los espacios de reunión de las asociaciones romanas. Diálogos desde la arqueología y la historia, 378-388. Sevilla: Universidad de Sevilla.

Oria Segura, Mercedes. 2012. "Sacerdotisas y devotas en la Hispania Antigua: un acercamiento iconográfico». Spal 21: 75-88.

Polignac, François de y Pauline Schmitt Pantel, eds. 1998. Public et privé en Grèce ancienne: lieux, conduites, pratiques. Actes du colloque organisé à Paris les 15-17 mars 1995. Strasbourg: Université March Bloch - Centre de recherches sur le Proche-Orient et la Grèce antiques.

Ramallo, Sebastián. 2000. «La porticus post scaenam en la arquitectura teatral romana. Introducción al tema». Anales de prehistoria y arqueología 16: 87-120.

Renberg, Gil. 2017. Where dreams may come. Incubation sanctuaries in the Greco-Roman world. Leiden-Boston: Brill.

Renberg, Gil. 2018. «Dreams and other divine communications from the Isiac gods in the Greek and Latin epigraphical record». En The Greco-Roman cults of Isis. Agents, images and practices. Proceedings of the VIth International Conference of Isis Studies (Erfurt, May 6-8 2013 - Liège, September 23-24 2013), ed. Valentino Gasparini y Richard Veymiers, vol. 1, 649-671. Leiden-Boston: Brill.

Rodríguez, Oliva. 2004. El teatro romano de Itálica. Estudio arqueoarquitectónico. Madrid: Universidad Autónoma de Madrid.

Rogers, Guy. 1991a. The sacred identity of Ephesos. Foundation myths of a Roman city. Londres - Nueva York: Routledge.

Rogers, Guy. 1991b. «Demosthenes of Enoanda and models of evergetism». JRS 81: 91-100.

Rosso, Emmanuelle. 2009. "Le message religieux des statues divines et imperials dans les théâtres romains: approche contextuelle et typologique». En Fronts de scene et lieux de culte dans le theatre antique, 89-126. Lyon: Maison de l'Orient.

Tantimonaco, Silvia. 2016. «Causae dedicationum nelle iscrizioni sacre. L'esempio della Lusitania romana». En Sacrum facere. Atti del III Seminario di Archeologia del Sacro. Lo spazio del 'sacro': ambienti e gesti del rito, Trieste, 3-4 ottobre 2014, ed. Federica Fontana y Emanuela Murgia, 455-478. Trieste: Edizioni Università di Trieste.

Veyne, Paul. 1986. «Une evolution du paganisme gréco-romain: injustice et piété des dieux, leurs orders ou 'oracles'». Latomus 45: 259283.

Wild, Robert. 1981. Water in the worship of Isis and Sarapis. Leiden: Brill.

Zugravu, Nelu. 1996-1997. "Les formules ex visu et ex iussu dans l'épigraphie de la Dacie romaine». Studia Antiqua et Archaeologica 3-4: 127-140. 